\title{
A mechanism for reducing the specific surface area of polycrystalline magnesium hydroxide
}

\author{
Akira YOSHIDA ${ }^{\dagger}$ and Ryuichi KOMATSU* \\ Technical Section, Technical Dept., Ube Material Industries, Ltd., 1985, Kogushi, Ube, Yamaguchi 755-8510 \\ *Graduate School of Science and Engineering, Yamaguchi University, 2-16-1, Tokiwadai, Ube, Yamaguchi 755-8611
}

\begin{abstract}
Magnesium hydroxide powder is used as a flame retardant in resin cable and wire sheathing. To be considered effective as a flame retardant, magnesium hydroxide needs to consist of primary particles having a diameter of $0.5-1.5 \mu \mathrm{m}$ and has to be less cohesive with a small specific surface area of $5 \mathrm{~m}^{2} \cdot \mathrm{g}^{-1}$. However, magnesium hydroxide obtained from seawater and slaked lime slurry consists of polycrystalline secondary particles with an average diameter of about $3 \mu \mathrm{m}$ that result form scaleshaped primary particles and have a high specific surface area of over $10 \mathrm{~m}^{2} \cdot \mathrm{g}^{-1}$, making magnesium hydroxide highly hygroscopic and thus unsuitable for application as a flame-retardant. In this study, a mechanism for reducing the specific surface area of polycrystalline magnesium hydroxide powder was investigated to reduce its hygroscopicity. The Brunauer-EmmettTeller (BET) specific surface area was found to change depending on the drying rate and could be reduced upon dehydration at a low drying rate. A mechanism for reducing the BET specific surface area of magnesium hydroxide was identified: when magnesium hydroxide was dehydrated at a low drying rate, the decreasing drying period increased and the supersaturation of magnesium hydroxide by the moisture remaining in the pores was prolonged. Consequently, the primary particles of magnesium hydroxide grew larger, and the number of 3-10 nm sized pores, particularly 3-5 nm pores, in the polycrystalline secondary particles significantly decreased, thereby reducing the BET specific surface area.
\end{abstract}

(C2009 The Ceramic Society of Japan. All rights reserved.

Key-words : Magnesium hydroxide, Polycrystalline, Hygroscopicity, Specific surface area, Pore volume

[Received August 11, 2009; Accepted October 15, 2009]

\section{Introduction}

Magnesium hydroxide powder is used for plastic applications, particularly as a flame-retardant plastic material for cable and wire sheathing. In recent years, polyolefin resins such as polyethylene and polypropylene have been flame retarded for global environmental protection. ${ }^{1), 2)}$

For magnesium hydroxide powder to be effectively used as a flame retardant, it is necessary to develop powder consisting of primary particles with an average diameter of $0.5-1.5 \mu \mathrm{m}$, with less cohesivity, and having a small specific surface area of $5 \mathrm{~m}^{2} \cdot \mathrm{g}^{-1}$. Many studies have reported on magnesium hydroxide with such properties. Such magnesium hydroxide can be obtained by hydrating magnesium oxide or by hydrothermal synthesis. ${ }^{3)-8)}$ Nakanishi et al. ${ }^{3)}$ obtained about $1 \mu \mathrm{m}$ hexagonal magnesium hydroxide plates and $0.5-1 \mu \mathrm{m}$ hexagonal magnesium hydroxide columns with a uniform particle size by adding magnesium acetate or magnesium chloride while hydrating pulverized sintered magnesium powder as a raw material. Nishiue et al. ${ }^{6)}$ obtained magnesium hydroxide with a BrunauerEmmett-Teller (BET) specific surface area of $4-10 \mathrm{~m}^{2} \cdot \mathrm{g}^{-1}$ by hydrothermal synthesis.

On the other hand, magnesium hydroxide used for the production of a desulfurizer for exhaust gases, a neutralizing agent for the disposal of acid wastes and sintered magnesia, is obtained by adding an alkali source, such as slaked lime slurry, to seawater and reacting about $1250 \mathrm{mg} \cdot \mathrm{l}^{-1}$ magnesium ions in seawater with the alkali source. Because the primary size of the magnesium

Corresponding author: A. Yoshida; E-mail: akira.yoshida@ ubematerials.co.jp hydroxide is very small, i.e., less than $200 \mathrm{~nm}$, several problems arise while dehydrating and washing magnesium hydroxide. Therefore, these procedures are performed in the presence of seed crystals to increase the size of secondary particles. Consequently, magnesium hydroxide slurry is obtained that contains spherical secondary particles resulting from scale-shaped primary particles. Magnesium hydroxide powder is obtained by washing, dehydrating, and drying magnesium hydroxide slurry (hereinafter, the seawater process).9),10) However, magnesium hydroxide powder obtained by this process consist of secondary particles with an average diameter of 3-4 $\mu \mathrm{m}$ resulting from scale-shaped primary particles and has a high BET specific surface area over $10 \mathrm{~m}^{2} \cdot \mathrm{g}^{-1}$, with higher hygroscopicity.

If moist magnesium hydroxide powder is used as a flame retardant in resin products such as cable and wire sheathing, the moisture evaporates when the powder is mixed with resin, causing damage to the appearance of the resin products by foaming and reducing strength. To control particle size and specific surface area of magnesium hydroxide powder obtained by the seawater process, many studies have reported that the particle size and cohesion of magnesium hydroxide can be varied depending on the magnesium salt and alkali source. ${ }^{11)-14)}$ Ishihara et al. ${ }^{15)}$ reported that when magnesium methoxide $\mathrm{Mg}\left(\mathrm{OCH}_{3}\right)_{2}$ was hydrolyzed at a $90^{\circ} \mathrm{C}$ saturated steam, magnesium hydroxide crystallites grew larger when held at that temperature for an extended period of time. However, they did not report a reduced specific surface area and improved hygroscopicity during the drying stage of the magnesium hydroxide cake.

This study investigated a mechanism for reducing the BET specific surface area of magnesium hydroxide to improve the hygroscopicity of polycrystalline magnesium hydroxide powder, 
which consisted of secondary particles having an average particle size of 3-4 $\mu \mathrm{m}$ resulting from scale-shaped primary particles obtained by the seawater process.

\section{Test sample}

In the seawater process, magnesium hydroxide slurry ${ }^{16), 17)}$ (Ube Material Industries, Ltd.) with high $\mathrm{MgO}$ and low $\mathrm{B}_{2} \mathrm{O}_{3}$ content was used as a magnesium hydroxide cake having a moisture content of 22 mass \% wet basis (mass\%-WB). This cake was obtained by dehydrating the slurry using a pressure dehydrator. Table 1 shows the chemical composition and average particle size of dry magnesium hydroxide powder, and Fig. 1 shows the microstructure of the powder. It is evident from the microstructure that the powder consisted of secondary particles formed by the aggregation of primary particles of less than $200 \mathrm{~nm}$ size.

\section{Experimental method}

\subsection{Dry test method}

In order to adjust the drying rate of the magnesium hydroxide cake, low-temperature and humidity chambers (THN052PB, Toyo Seisakusho Kaisha, Ltd.) were used to obtain the temperature of $85-90^{\circ} \mathrm{C}$ and relative humidity (RH) of $25-65 \%$. A $100 \mathrm{~g}$ of magnesium hydroxide cake with a moisture content of 22 mass\%-WB in a mullite CW (Nikkato Co.) evaporating dish was placed in the low-temperature and humidity chambers, allowed to stand for a given time, and removed from the chamber. Next, the moisture was removed by using a constant temperature drying oven (OF-600, AS ONE Co.), which was set at $180^{\circ} \mathrm{C}$.

\subsection{Surface treatment}

Magnesium hydroxide powder with a reduced BET specific surface area was surface treated. During the surface treatment, $2000 \mathrm{~g}$ of ion exchange water was placed in $3 \mathrm{l}$ beakers and heated to $70^{\circ} \mathrm{C}$. Next, $3 \mathrm{~g}$ of sodium stearate (NONSOUL SN15 , NOF Co.) was added as a surface treatment agent to the ion exchange water and stirred for $10 \mathrm{~min}$ to dissolve the agent. Subsequently, $100 \mathrm{~g}$ of magnesium hydroxide powder with a reduced BET specific surface area was added to the solution containing the surface treatment agent and stirred for $1 \mathrm{~h}$ at a constant temperature of $70^{\circ} \mathrm{C}$. The slurry containing the dispersed magnesium hydroxide was suction-filtered using a Buchner funnel. The cake was washed with 21 of ion-exchanged water to remove sodium. The resultant cake was dried for $12 \mathrm{~h}$ in the constant temperature

Table 1. Chemical Composition and Average Particle Size of Magnesium Hydroxide Powder

\begin{tabular}{|c|c|c|c|c|c|c|}
\hline \multicolumn{6}{|c|}{ Chemical composition/mass\% } & \multirow{2}{*}{$\begin{array}{c}\text { Average } \\
\text { particle size } \\
\quad / \mu \mathrm{m}\end{array}$} \\
\hline $\mathrm{Mg}(\mathrm{OH})_{2}$ & $\mathrm{CaO}$ & $\mathrm{SiO}_{2}$ & $\mathrm{Fe}_{2} \mathrm{O}_{3}$ & $\mathrm{Al}_{2} \mathrm{O}_{3}$ & $\mathrm{~B}_{2} \mathrm{O}_{3}$ & \\
\hline 97.21 & 0.13 & 0.11 & 0.02 & 0.02 & 0.02 & 3.5 \\
\hline
\end{tabular}
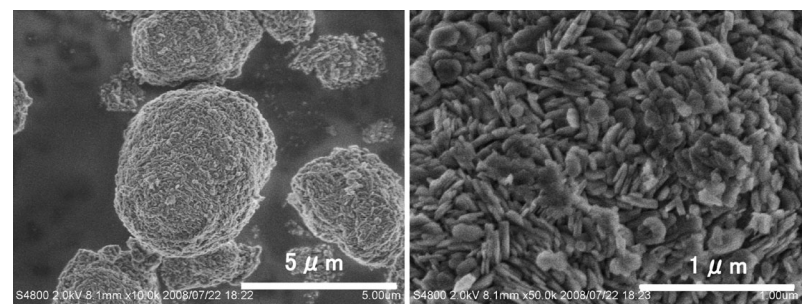

Fig. 1. Microstructure of polycrystalline magnesium hydroxide powder. drying oven set at $120^{\circ} \mathrm{C}$ to obtain surface-treated magnesium hydroxide powder.

\subsection{Moisture absorption test}

In the moisture absorption test, surface-treated and nonsurface treated magnesium hydroxide powder were placed in the low-temperature and humidity chambers set at $30^{\circ} \mathrm{C}$ and $80 \% \mathrm{RH}$, and the mass of the magnesium hydroxide powder was measured, first for every $30 \mathrm{~min}$ up to $180 \mathrm{~min}$ after insertion into the humidity chamber, and subsequently, every $60 \mathrm{~min}$. The mass increase rate was calculated as hygroscopicity.

\subsection{Characterization}

The average particle size of the magnesium hydroxide powder was measured by using the Microtrack 9320HRA X-100 (NIKKISO Co., Ltd.).

The specific surface area was measured by MONOSORB (Yuasa Ionics Inc.), a BET single-point specific surface areameasuring device. Prior to the measurement, the sample was deaerated at $150^{\circ} \mathrm{C}$ for $10 \mathrm{~min}$.

The pore volume was measured by AUTOSORB-3B (Yuasa Ionics Inc.), a fully automatic gas adsorption analyzer. Prior to the measurement, the sample was deaerated at $150^{\circ} \mathrm{C}$ for $10 \mathrm{~min}$. Desorption isotherms were then measured by the nitrogen absorption method. On the basis of the desorption isotherm data, the specific surface area-based log-derived pore volume was calculated by the Barrett-Joyner-Halenda (BJH) method. The crystallite size was measured by X-ray powder diffraction (XRD) using the X-ray diffractometer RINT2000 (Rigaku Co.). Using silicon as the reference material, the average crystallite size of $D_{110}$ and $D_{001}$ was calculated by Scherrer's equation using the half-value width of the X-ray powder pattern of faces (110) and (100) of magnesium hydroxide. In addition, the lattice spacing $\mathrm{d}_{110}$ and $\mathrm{d}_{001}$ were measured. The microstructure was observed using a field emission scanning electron microscope (FE-SEM) S-4800 (Hitachi High-Technologies Co.).

\section{Results and discussion}

\subsection{Results of the dry test}

Figure 2 shows the change in the chamber temperature and material temperature and wet-basis moisture content of the magnesium hydroxide cake when $100 \mathrm{~g}$ of magnesium hydroxide cake with a moisture content of 22 mass \%-WB in the CW evaporating dish was placed in the low-temperature and humidity chambers set at $85^{\circ} \mathrm{C}$ and $65 \% \mathrm{RH}$ and maintained in the conditions for $3-72 \mathrm{~h}$.

Figure 3 shows the change in the BET specific surface area of magnesium hydroxide powder that was allowed to stand for a given time and removed from the chambers, and then was processed for moisture removal in the constant temperature drying oven set at $180^{\circ} \mathrm{C}$. The material temperature rose to $76.8^{\circ} \mathrm{C}$ in $3 \mathrm{~h}, 84.0^{\circ} \mathrm{C}$ in $12 \mathrm{~h}$, and $84.9^{\circ} \mathrm{C}$ in $24 \mathrm{~h}$. After $24 \mathrm{~h}$, the temperature remained constant at $85^{\circ} \mathrm{C}$. The moisture content rapidly decreased to 8.8 mass \%-WB and 2.6 mass $\%-W B$ in $3 \mathrm{~h}$ and $6 \mathrm{~h}$, respectively; it continued to decrease to 1.1 mass $\%$-WB and 0.9 mass $\%$-WB in $12 \mathrm{~h}$ and $24 \mathrm{~h}$, respectively. After $24 \mathrm{~h}$, it remained constant within a range of $0.8-0.9$ mass $\%$-WB. The BET specific surface area of a sample that was not placed in the low-temperature and humidity chambers and was not processed for moisture removal at $180^{\circ} \mathrm{C}$ (hereinafter, the $0 \mathrm{~h}$ sample or $0 \mathrm{~h}$-held sample) was $12.5 \mathrm{~m}^{2} \cdot \mathrm{g}^{-1}$ at $0 \mathrm{~h}$ and $12.4 \mathrm{~m}^{2} \cdot \mathrm{g}^{-1}$ at $3 \mathrm{~h}$, showing little change. The BET surface area decreased to $10.1 \mathrm{~m}^{2} \cdot \mathrm{g}^{-1}$ in $6 \mathrm{~h}, 6.7 \mathrm{~m}^{2} \cdot \mathrm{g}^{-1}$ in $12 \mathrm{~h}, 6.0 \mathrm{~m}^{2} \cdot \mathrm{g}^{-1}$ in $24 \mathrm{~h}$, and 


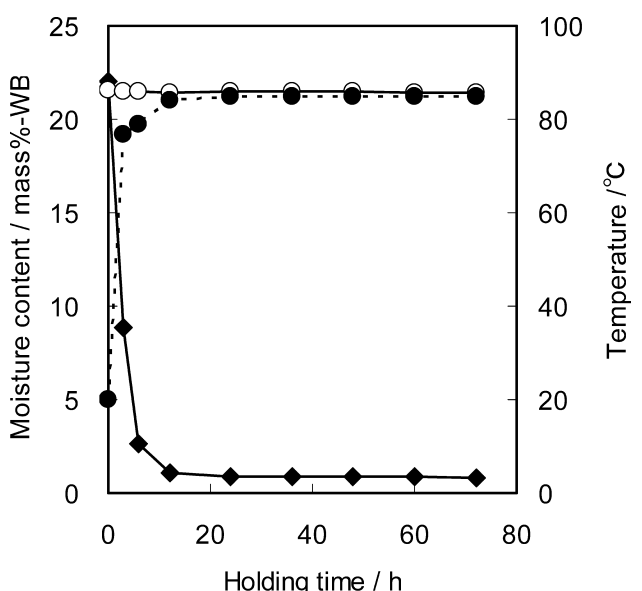

Fig. 2. Moisture content of magnesium hydroxide cake and temperature profile after dry test at $85^{\circ} \mathrm{C}$ and $65 \% \mathrm{RH}(\bigcirc$ : Chamber temperature, Material temperature, $\bullet$ : Moisture content of magnesium hydroxide cake).

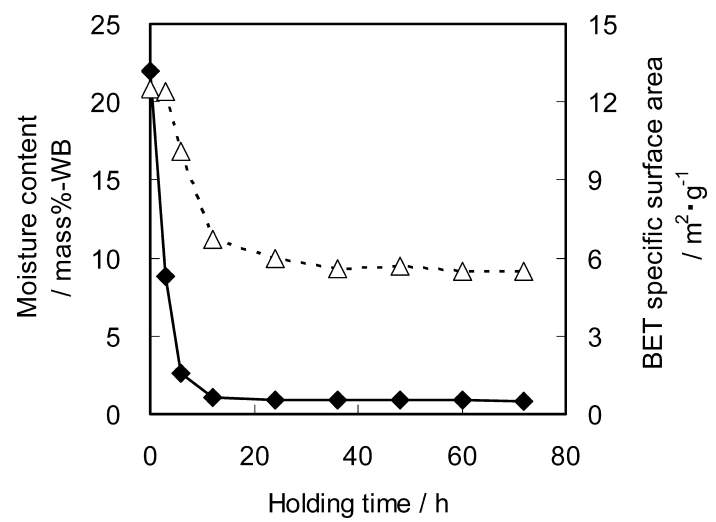

Fig. 3. Change of BET specific surface area of magnesium hydroxide powder after dry test at $85^{\circ} \mathrm{C}$ and $65 \% \mathrm{RH}$ ( $\bullet$ : Moisture content of magnesium hydroxide cake, $\triangle$ : BET specific surface area of magnesium hydroxide powder).

$5.6 \mathrm{~m}^{2} \cdot \mathrm{g}^{-1}$ in $36 \mathrm{~h}$, and particularly decreased rapidly between the holding times of 6 and $12 \mathrm{~h}$.

Figures $\mathbf{4}$ and $\mathbf{5}$ show the change in the moisture content and BET specific surface area of magnesium hydroxide placed at $90^{\circ} \mathrm{C}$ and $65 \% \mathrm{RH}$ and $85^{\circ} \mathrm{C}$ and $25 \% \mathrm{RH}$, respectively. The moisture content of the magnesium hydroxide placed at $90^{\circ} \mathrm{C}$ and $65 \% \mathrm{RH}$ was similar to that placed at $85^{\circ} \mathrm{C}$ and $65 \% \mathrm{RH}$. At $85^{\circ} \mathrm{C}$ and a low $\mathrm{RH}$ of $25 \%$, the moisture content rapidly decreased to 10.9 mass $\%$-WB in $1 \mathrm{~h}$ and 5.5 mass $\%$-WB in $2 \mathrm{~h}$, and continued to decrease to 1.2 mass $\%-\mathrm{WB}$ in $4 \mathrm{~h}$ and 0.7 mass \%-WB in $5 \mathrm{~h}$. After $5 \mathrm{~h}$, the moisture content remained constant within a range of 0.5-0.7 mass\%-WB. The BET specific surface area showed little change up to the holding time of $2 \mathrm{~h}$, when it was $12.1 \mathrm{~m}^{2} \cdot \mathrm{g}^{-1}$. It decreased to $11.5 \mathrm{~m}^{2} \cdot \mathrm{g}^{-1}$ in $3 \mathrm{~h}$ and $10.4 \mathrm{~m}^{2} \cdot \mathrm{g}^{-1}$ in $5 \mathrm{~h}$. After $9 \mathrm{~h}$, it remained constant within a range of $9-10 \mathrm{~m}^{2} \cdot \mathrm{g}^{-1}$. The BET surface area decreased between the holding times of 2 and $9 \mathrm{~h}$, but there was a decrease of only $3 \mathrm{~m}^{2} \cdot \mathrm{g}^{-1}$. The test showed that the BET specific surface area of the magnesium hydroxide powder could be changed by changing the drying conditions of the magnesium hydroxide cake.

\subsection{Results of the moisture absorption test}

Figure 6 shows the change in the hygroscopicity of magne-

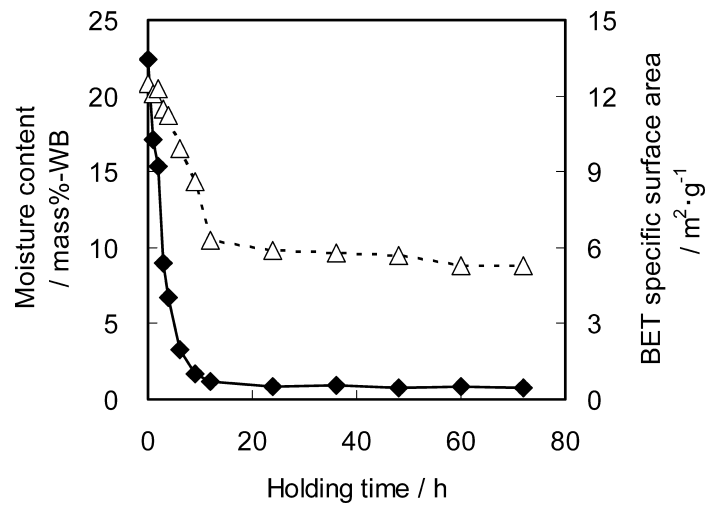

Fig. 4. Change of BET specific surface area of magnesium hydroxide powder after dry test at $90^{\circ} \mathrm{C}$ and $65 \% \mathrm{RH}(\diamond$ : Moisture content of magnesium hydroxide cake, $\triangle$ : BET specific surface area of magnesium hydroxide powder).

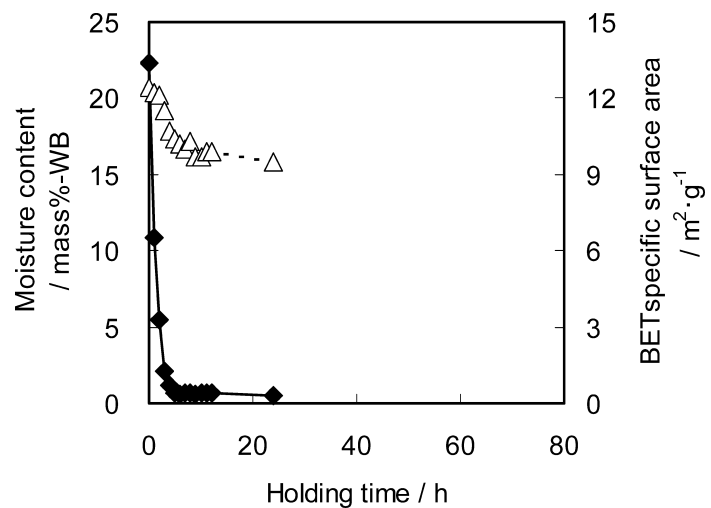

Fig. 5. Change of BET specific surface area of magnesium hydroxide powder after dry test at $85^{\circ} \mathrm{C}$ and $25 \% \mathrm{RH}(\diamond$ : Moisture content of magnesium hydroxide cake, $\triangle$ : BET specific surface area of magnesium hydroxide powder).

sium hydroxide powder samples subjected to the dry test at $90^{\circ} \mathrm{C}$ and $65 \% \mathrm{RH}$. The following samples were used: a 0 h-held sample with a BET specific surface area of $12.5 \mathrm{~m}^{2} \cdot \mathrm{g}^{-1}$, a $6 \mathrm{~h}$-held sample with a BET specific surface area of $9.9 \mathrm{~m}^{2} \cdot \mathrm{g}^{-1}$, a $24 \mathrm{~h}-$ held sample with a BET specific surface area of $5.9 \mathrm{~m}^{2} \cdot \mathrm{g}^{-1}$, and a surface-treated sample prepared by adding 3 mass $\%$ sodium stearate to $24 \mathrm{~h}$-held magnesium hydroxide powder. The hygroscopicity after $360 \mathrm{~min}$ was 1.05 mass $\%, 0.93$ mass $\%$, 0.68 mass $\%$, and 0.39 mass $\%$ for the 0 h-held sample, 6 h-held sample, 24 h-held sample, and 24 h-held surface-treated sample, respectively. As the BET specific surface area decreased, the hygroscopicity decreased. The hygroscopicity of the surfacetreated sample decreased even further, indicating the effectiveness of surface treatment in improving the hygroscopicity.

\subsection{Mechanism for reducing the BET specific sur- face area}

It was observed that the BET specific surface area could be reduced by changing the drying conditions of the magnesium hydroxide cake. The change in pore volume was investigated by the nitrogen adsorption method to determine the mechanism of the specific surface area decrease. Figure 7 shows the change in the log-derived pore volume of magnesium hydroxide powder samples with different BET specific surface areas subjected to the dry test at $90^{\circ} \mathrm{C}$ and $65 \% \mathrm{RH}$. The following samples were 


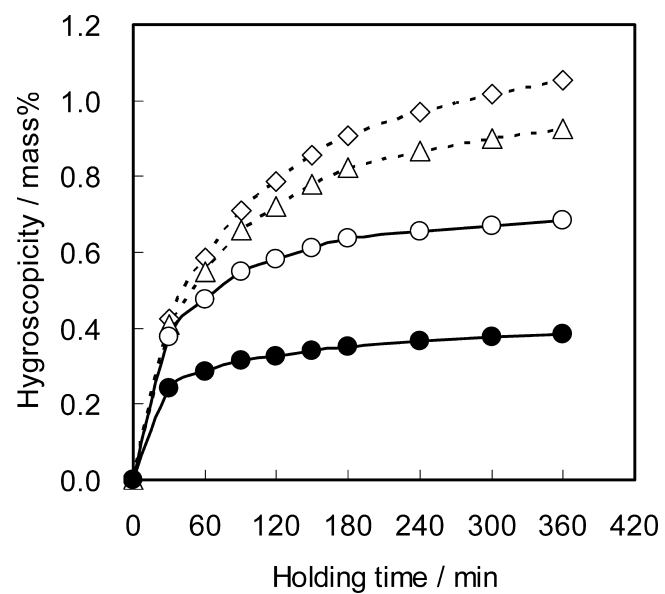

Fig. 6. Change of hygroscopicity of magnesium hydroxide powder after dry test at $90^{\circ} \mathrm{C}$ and $65 \% \mathrm{RH}(\diamond:$ Holding time $0 \mathrm{~h}, \triangle$ : Holding time $6 \mathrm{~h}$, $\bigcirc$ : Holding time $24 \mathrm{~h}, \mathbf{0}$ : Holding time $24 \mathrm{~h}+$ surface treatment(sodium stearate)).

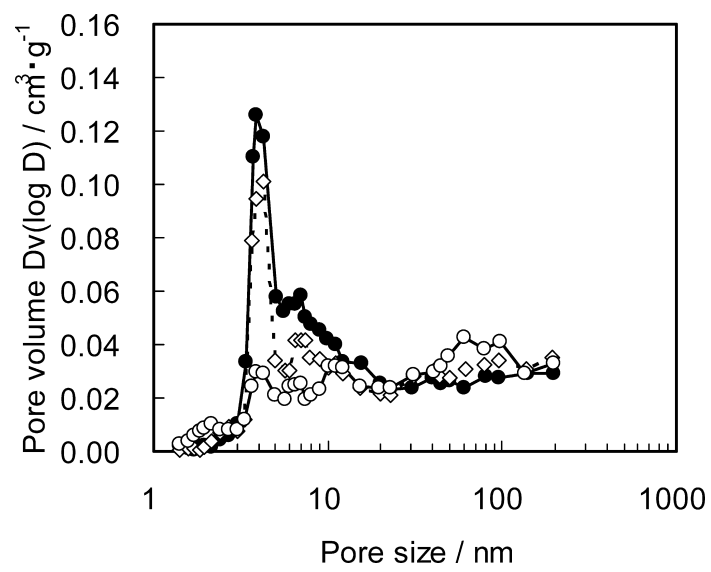

Fig. 7. Change of in log-derived pore volume of magnesium hydroxide powder after dry test at $90^{\circ} \mathrm{C}$ and $65 \% \mathrm{RH}(\bullet$ : Holding time $0 \mathrm{~h}, \diamond$ : Holding time 6 h, $\bigcirc$ : Holding time 24 h).

tested: a 0 h-held sample with a BET specific surface area of $12.5 \mathrm{~m}^{2} \cdot \mathrm{g}^{-1}$, a $6 \mathrm{~h}$-held sample with a BET specific surface area of $9.9 \mathrm{~m}^{2} \cdot \mathrm{g}^{-1}$, and a sample with a BET specific surface area of $5.9 \mathrm{~m}^{2} \cdot \mathrm{g}^{-1}$. The pore volume showed a high peak of $0.13 \mathrm{~cm}^{3} \cdot \mathrm{g}^{-1}$ between the pore sizes $3-5 \mathrm{~nm}$ in the $0 \mathrm{~h}$-held sample, and decreased to $0.10 \mathrm{~cm}^{3} \cdot \mathrm{g}^{-1}$ and $0.03 \mathrm{~cm}^{3} \cdot \mathrm{g}^{-1}$ in the $6 \mathrm{~h}$-held and 24 h-held samples, respectively, as the BET specific surface area decreased. The pore volume of the 0 h-held sample had a peak of $0.06 \mathrm{~cm}^{3} \cdot \mathrm{g}^{-1}$ at the pore size of $7 \mathrm{~nm}$ in a range of $5-10 \mathrm{~nm}$. As the BET specific surface area decreased, the pore volume decreased to $0.04 \mathrm{~cm}^{3} \cdot \mathrm{g}^{-1}$ and $0.02 \mathrm{~cm}^{3} \cdot \mathrm{g}^{-1}$ in the $6 \mathrm{~h}$-held and 24 h-held samples, respectively.

Figure 8 shows the change in log-derived pore volume at $85^{\circ} \mathrm{C}$ and a low RH of $25 \%$ for the 3 samples with a difference of about $3 \mathrm{~m}^{2} \cdot \mathrm{g}^{-1}$ in BET specific surface area: the 0 h-held sample with a BET specific surface area of $12.4 \mathrm{~m}^{2} \cdot \mathrm{g}^{-1}, 4 \mathrm{~h}$-held sample with a BET specific surface area of $10.7 \mathrm{~m}^{2} \cdot \mathrm{g}^{-1}$, and $9 \mathrm{~h}-$ held sample with a BET specific surface area of $9.7 \mathrm{~m}^{2} \cdot \mathrm{g}^{-1}$. The pore volume in the pore size range $3-5 \mathrm{~nm}$ was $0.13 \mathrm{~cm}^{3} \cdot \mathrm{g}^{-1}$ in the $0 \mathrm{~h}$-held sample, $0.10 \mathrm{~cm}^{3} \cdot \mathrm{g}^{-1}$ in the $4 \mathrm{~h}$-held sample, and $0.09 \mathrm{~cm}^{3} \mathrm{~g}^{-1}$ in the $9 \mathrm{~h}$-held sample, which did not decrease unlike at $90^{\circ} \mathrm{C}$ and $65 \% \mathrm{RH}$. Similarly, the pore volume at a pore

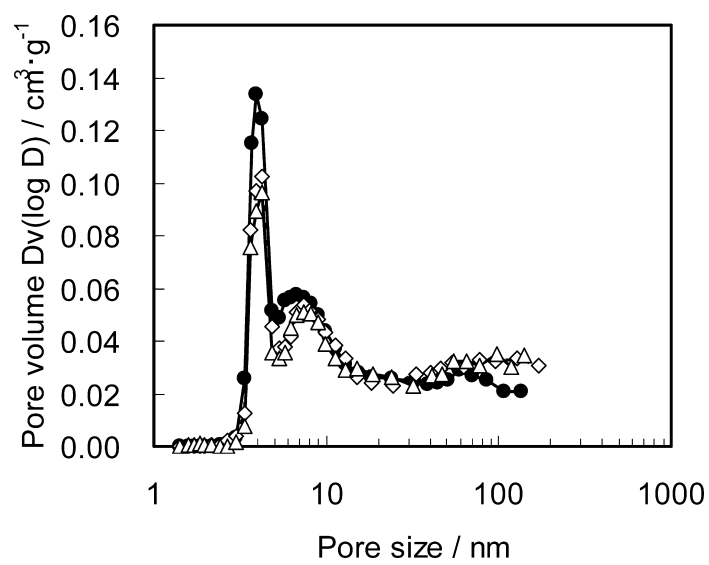

Fig. 8. Change in log-derived pore volume of magnesium hydroxide powder after dry test at $85^{\circ} \mathrm{C}$ and $25 \% \mathrm{RH}(\bullet$ : Holding time $0 \mathrm{~h}, \diamond$ : Holding Time $4 \mathrm{~h}, \triangle$ : Holding time 9 h).

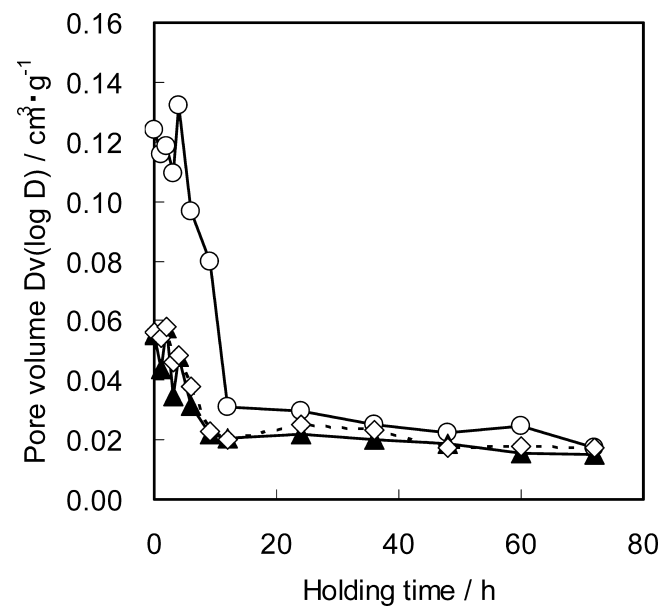

Fig. 9. Change in 3-5 nm, 5-6 nm and 6-7 nm of log-derived pore volume of magnesium hydroxide powder after dry test at $90^{\circ} \mathrm{C}$ and $65 \% \mathrm{RH}$ ( $\bigcirc$ : Pore size 3-5 nm, $\mathbf{\Delta}$ : Pore size 5-6 nm, $\diamond$ Pore size 6-7 nm).

size of $7 \mathrm{~nm}$ was $0.06 \mathrm{~cm}^{3} \cdot \mathrm{g}^{-1}$ in the 0 h-held sample and $0.05 \mathrm{~cm}^{3} \cdot \mathrm{g}^{-1}$ in the $9 \mathrm{~h}$-held sample, which also did not decrease.

Figure 9 shows the change in pore volume in samples with different pore size ranges of 3-5 nm, 5-6 nm, and 6-7 nm versus the holding time at $90^{\circ} \mathrm{C}$ and $65 \% \mathrm{RH}$. In all the pore size ranges, there was no consistent decrease in the pore volume. The pore volume showed an increase and decrease up to a holding time of $3 \mathrm{~h}$ for all the size ranges, particularly for the 5-6 nm size. In a size range of 3-7 nm, a decrease in pore size in the 6-7 nm size entailed an increase in pore volume for the size range of 5-6 nm, and a decrease in the pore size for the 5-6 nm diameter range entailed an increase in pore volume for the $3-5 \mathrm{~nm}$ size range. This is probably why the increase and decrease in pore volume occurred in different pore size ranges. The pore volume decreased between the holding times of 4 and $12 \mathrm{~h}$ in all the size ranges, particularly between 9 and $12 \mathrm{~h}$ in the $3-5 \mathrm{~nm}$ size range. As the moisture content of the cake between 9 and $12 \mathrm{~h}$ decreased by about 0.5 mass $\%$-WB from 1.7 to 1.2 mass $\%$-WB, the pore volume showed a decrease of $0.05 \mathrm{~cm}^{3} \cdot \mathrm{g}^{-1}$.

The decreasing drying rate during the period of the large change in BET specific surface area at different temperatures and relative humidities was calculated. The decreasing drying rate $R_{d}$ 
$\left[\mathrm{kg} \cdot \mathrm{m}^{-2} \cdot \mathrm{h}^{-1}\right]$ was calculated for the moisture content at holding times of $3-36 \mathrm{~h}$ at $85^{\circ} \mathrm{C}$ and $65 \% \mathrm{RH}, 3-24 \mathrm{~h}$ at $90^{\circ} \mathrm{C}$ and $65 \% \mathrm{RH}$, and $2-6 \mathrm{~h}$ at $85^{\circ} \mathrm{C}$ and $25 \% \mathrm{RH}^{18)}$ In general, the decreasing drying rate $\mathrm{R}_{\mathrm{d}}$ is expressed by the following equation:

$$
\mathrm{R}_{\mathrm{d}}=(\mathrm{W} / \mathrm{A})(-\mathrm{d} \omega / \mathrm{d} \theta)
$$

where $W$ is the mass of the completely dried magnesium hydroxide in absolute mass [kg], and $A$ is the area of the top surface of magnesium hydroxide placed in the $\mathrm{CW}$ evaporating dish in a dry area $\left[\mathrm{m}^{2}\right]$ of $0.00608 \mathrm{~m}^{2}$. Figure 10 shows the relationship between the moisture content $\omega$ [mass\%-WB] and the decreasing drying rate. The decreasing drying rate curves were linear for all the conditions. The gradient of the linear approximation curve obtained was 0.0044 for $90^{\circ} \mathrm{C}$ and $65 \% \mathrm{RH}, 0.0056$ for $85^{\circ} \mathrm{C}$ and $65 \% \mathrm{RH}$, and 0.0133 for $85^{\circ} \mathrm{C}$ and $25 \% \mathrm{RH}$. The drying rate at $90^{\circ} \mathrm{C}$ and $65 \% \mathrm{RH}$ was about one-third of that at $85^{\circ} \mathrm{C}$ and $25 \%$ RH.

Table 2 shows the crystallite size $\mathrm{D}_{001}$ and $\mathrm{D}_{110}$ and lattice spacing $\mathrm{d}_{110}$ and $\mathrm{d}_{001}$ of magnesium hydroxide after holding times of $0,6,24$, and $72 \mathrm{~h}$ in the dry test at $90^{\circ} \mathrm{C}$ and $65 \% \mathrm{RH}$. XRD analysis showed an increase in both the crystallite sizes with increasing holding time and thus crystal growth. Both lattice spacings remained nearly unchanged. Crystal growth occurred during drying to the equilibrium moisture content and continued for a holding time of $24 \mathrm{~h}$ after the equilibrium moisture content was reached.

Figure 11 shows the surface of magnesium hydroxide after holding times of 0 and $72 \mathrm{~h}$ in the dry test at $90^{\circ} \mathrm{C}$ and $65 \% \mathrm{RH}$. Although not clearly shown in the figure, the crystallite size was larger in the $72 \mathrm{~h}$-held sample than in the 0 h-held sample, confirming the XRD analysis results on the crystallite size. Sharper

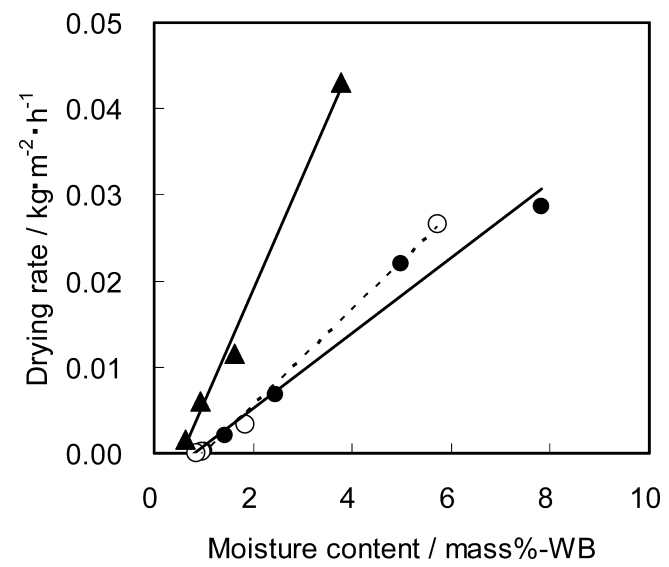

Fig. 10. Change of decreasing drying rate of magnesium hydroxide powder $\left(\bullet: 90^{\circ} \mathrm{C}-65 \% \mathrm{RH}, y=0.0044 x-0.0035, \bigcirc: 85^{\circ} \mathrm{C}-65 \% \mathrm{RH}, y=\right.$ $0.0056 x-0.0055, \mathbf{\Delta}: 85^{\circ} \mathrm{C}-25 \% \mathrm{RH}, y=0.0133 x-0.0076$ ).

Table 2. Change of Crystallite Size and Lattice Spacing on Magnesium Hydroxide After Dry Test at $90^{\circ} \mathrm{C}$ and $65 \% \mathrm{RH}$

\begin{tabular}{ccccc}
\hline \multirow{2}{*}{$\begin{array}{c}\text { Holding } \\
\text { time/h }\end{array}$} & \multicolumn{2}{c}{ Crystallite size/nm } & \multicolumn{2}{c}{ Lattice spacing/nm } \\
\cline { 2 - 5 } & $\mathrm{D}_{001}$ & $\mathrm{D}_{110}$ & $\mathrm{~d}_{001}$ & $\mathrm{~d}_{110}$ \\
\hline 0 & 23.9 & 49.0 & 0.4782 & 0.1573 \\
6 & 24.2 & 49.0 & 0.4782 & 0.1573 \\
24 & 24.6 & 49.5 & 0.4782 & 0.1573 \\
72 & 25.9 & 55.6 & 0.4782 & 0.1573 \\
\hline
\end{tabular}

crystalline ridges were observed.

The reduction mechanism of the BET specific surface area of magnesium hydroxide is discussed below. The BET specific surface area decreased by approximately only $1 \mathrm{~m}^{2} \cdot \mathrm{g}^{-1}$ for moisture content of up to 5 mass \%-WB of the magnesium hydroxide cake, but decreased significantly for the moisture content of 2 mass\%WB to the equilibrium moisture content. The magnesium hydroxide used in the test consisted of polycrystalline secondary particles with an average particle size of about $3.5 \mu \mathrm{m}$ formed by the aggregation of primary particles of less than $200 \mathrm{~nm}$. Consequently, the moisture content in the secondary particles was reduced to about 5 mass $\%$-WB, and the polycrystalline secondary particles were dehydrated and dried. At this stage, there was little change in the BET surface area. Next, the capillary water in capillary tubes present in the pores of the polycrystalline secondary particles was removed, and the particles were dehydrated and dried.

As shown in Fig. 7, the pore volume did not decrease for pore size of more than $10 \mathrm{~nm}$, but decreased by over $0.02 \mathrm{~cm}^{3} \cdot \mathrm{g}^{-1}$ for those less than $10 \mathrm{~nm}$. This indicated that moisture in pores of less than $10 \mathrm{~nm}$ size was present in the form of capillary water. At $90{ }^{\circ} \mathrm{C}$ and $65 \% \mathrm{RH}$, the pore volume decreased, particularly when dehydration and evaporation occurred at a low drying rate (15 $\mathrm{h}$ for the moisture content of the cake to decrease from 5 mass $\%$-WB to the equilibrium water content). As mentioned above, the decrease in pore volume was probably due to the growth of primary particles of magnesium hydroxide. The solubility of magnesium hydroxide is very low, at $9 \times 10^{-3} \mathrm{~g} \cdot \mathrm{l}^{-1}$ in $18^{\circ} \mathrm{C}$ water. ${ }^{19)}$ However, magnesium hydroxide remaining in moisture was supersaturated when the water in capillary tubes present between the particles was removed and evaporated. When dehydration and evaporation occur at a low drying rate, supersaturation is maintained for an extended period of time, facilitating the growth of the primary particles of magnesium hydroxide. Due to this growth, for less than $10 \mathrm{~nm}$ pore sizes, $10 \mathrm{~nm}$ pores shrank first, and in the last stage the volume of $3-$ $5 \mathrm{~nm}$ pores decreased below $0.03 \mathrm{~cm}^{3} \mathrm{~g}^{-1}$. At $90^{\circ} \mathrm{C}$ and $25 \% \mathrm{RH}$, when dehydration and evaporation occur at a relatively high drying rate, at which it takes $3 \mathrm{~h}$ for the moisture content of the cake to decrease from 5 mass $\%$-WB to the equilibrium moisture con-

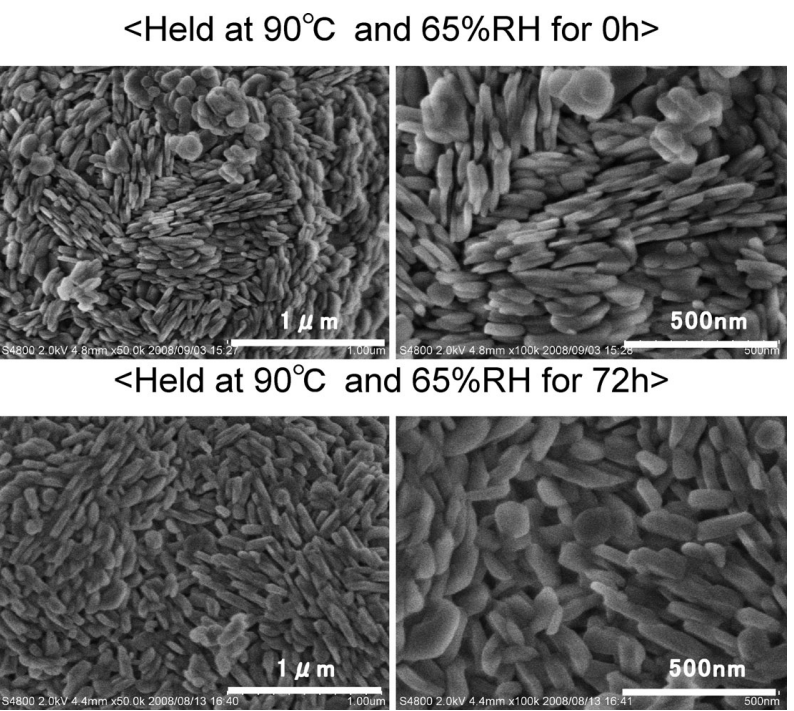

Fig. 11. Microstructure of polycrystalline magnesium hydroxide held at $90^{\circ} \mathrm{C}$ and $65 \% \mathrm{RH}$ 
tent, supersaturation was maintained for only a short period of time. Consequently, the primary particles of magnesium hydroxide grew, but pore volume did not decrease significantly.

XRD analysis of crystallite sizes showed that magnesium hydroxide continued to grow even $24 \mathrm{~h}$ after the equilibrium moisture content was reached. As reported by Ishihara et al., ${ }^{15)}$ when the hydrolysis of $\mathrm{Mg}\left(\mathrm{OCH}_{3}\right)_{2}$ was performed at $90^{\circ} \mathrm{C}$ saturated steam, the crystallite sizes $\mathrm{D}_{001}$ and $\mathrm{D}_{110}$ of magnesium hydroxide after being held for $100 \mathrm{~h}$ were 8.8 and $29.8 \mathrm{~nm}$, respectively. When the hydrolysis was carried out at $90^{\circ} \mathrm{C}$ and a low steam pressure $\left(\mathrm{P} / \mathrm{P}_{0}=0.33\right)$, the crystallite sizes $\mathrm{D}_{001}$ and $\mathrm{D}_{110}$ after being held at the abovementioned conditions for $100 \mathrm{~h}$ were 5.2 and $17.7 \mathrm{~nm}$, respectively. Hence, particles having smaller crystallite sizes were produced. Both the XRD analysis and the study of Ishihara et al. agree that steam significantly contributes to the crystal growth of magnesium hydroxide. The crystal growth of magnesium hydroxide in steam will be further investigated in the future.

\section{Conclusions}

In order to improve the hygroscopicity of polycrystalline magnesium hydroxide consisting of secondary particles with an average particle size of 3-4 $\mu \mathrm{m}$ that resulted from scale-shaped primary particles obtained by the seawater process, a reduction in BET specific surface area was studied. This study showed that the BET specific surface area could be changed by changing the drying rate, and that a BET specific surface area of more than $10 \mathrm{~m}^{2} \cdot \mathrm{g}^{-1}$ of magnesium hydroxide powder could be reduced to less than $6 \mathrm{~m}^{2} \cdot \mathrm{g}^{-1}$ when dehydration was carried out at a low drying rate. The hygroscopicity of polycrystalline magnesium hydroxide decreased as the BET specific surface area decreased. The hygroscopicity of stearic acid surface-treated magnesium hydroxide powder decreased even further.

A mechanism for reducing the BET specific surface area of magnesium hydroxide was identified: when magnesium hydroxide was dehydrated at a low drying rate, the decreasing drying period increased and the supersaturation of magnesium hydroxide by the moisture remaining in the pores was prolonged. Consequently, the primary particles of magnesium hydroxide grew larger and the number of 3-10 nm sized pores, particularly $3-5 \mathrm{~nm}$ pores, in polycrystalline secondary particles significantly decreased, reducing the BET specific surface area.

\section{References}

1) P. R. Hornsby and A. Mthupha, Soc. Plast. Eng. Annu. Tech. Conf., 51, 1954-1956 (1993).

2) T. Hirose, Nippon Gomu Kyokaishi, 75, 327-329 (2002).

3) K. Amita, K. Nakagawa, Y. Ikegami, T. Ishihara and G. Hashizume, J. Soc. Inrog. Mater, Japan (Gypsum \& Lime), 218, 29-34 (1989).

4) K. Nakanishi, T. Fukuda and J. Nomura, J. Ceram. Soc. Japan, 97, 683-689 (1989).

5) S. Kitahara and N. Furuta, Bullietin Fukuoka University of Education, 26, 69-75 (1976).

6) W. Nishiue and M. Komatsu, Japanese Patent, 57-100918 (1982).

7) S. Miyata, M. Kuroda, S. Okada, S. Okasaki and M. Takasu, Japanese Patent, 2-204321 (1990).

8) Q. L. Wu, L. Xiang and Y. Jin, Powder Tech., 165, 100-104 (2006).

9) A. Yoshida and N. Nishino, J. Soc. Inorg. Mater. Japan, 12, 548-553 (2005).

10) “Kagaku Binran Oyohen 3rd Edition," Ed. by The Chemical Society of Japan, Maruzen (1980) p. 39.

11) B. Wang, W. Zhang, W. Zhang, Y. Caiyuan, G. Wang, L. Huang and A. S. Mujumdar, Drying Technology, 25, 715-721 (2007).

12) H. Tsuge, Bull. Soc. Sea Water Sci. Japan, 51, 348-357 (1997).

13) R. Giorgi, C. Bozzi, L. Dei, C. Gabbiani, B. W. Ninham and P. Baglioni, Langmuir, 21[18], 8495-8501 (2005).

14) J. W. Mullin, J. D. Murphy, O. Soehnel and G. Spoors, Ind. Eng. Chem. Res., 28, 1725-1730 (1989).

15) T. Ishihara, K. Amita and G. Hashizume, Chem. Soc. Japan, 10, 1677-1683 (1988).

16) K. Yamamoto and A. Kaneyasu, "Preprint of the First International Conference of Refractories," (1983) pp. 223-236.

17) K. Yamamoto and A. Kaneyasu, Taikabutsu, 35[11], 628-631 (1983).

18) "Kagakukougaku Binran 3rd Edition," Ed. by The Society of Chemical Engineers, Japan, Maruzen (1968) p. 631.

19) M. A. Shand, "The Chemistry and Technology of Magnesia," Wiley-Interscience (2006) p. 33. 